\title{
Author Correction: Scanning near-field infrared microscopy
}

\section{Tom Vincent}

Correction to: Nature Reviews Physics https://doi.org/10.1038/s42254-021-00337-y, published online 01 June 2021.

The original article incorrectly cited a grant number. This has now been updated to GrapheneCore3, no. 881603.

https://doi.org/10.1038/s42254-021-00343-0 I Published online 7 June 2021

๑) Springer Nature Limited 2021 